\title{
Se prémunir pour l'avenir...
}

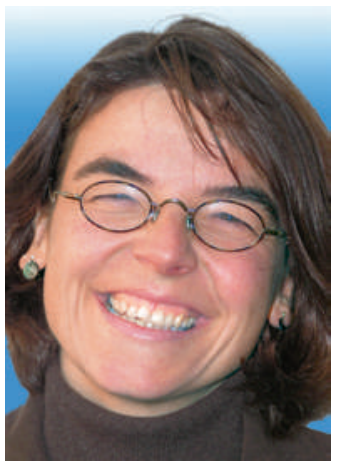

Christina Aus der Au
Je sors tout juste de convalescence. La grippe - pas la variante gastro-intestinale, heureusement, «juste» celle qui vous cloue au lit avec de la toux et une forte fièvre - a eu raison de moi. Toute une semaine, qui devait être bien remplie de réunions et de retraites, s'est évaporée dans les limbes de ma torpeur. Et malgré cela, la Terre a continué de tourner. Eh oui! Même sans moi...

De retour au bureau, j'ai été accueillie par de nombreux témoignages de bienvenue, même si certains sourires compatissants cachaient mal une certaine autosatisfaction: ces personnes s'étaient fait vacciner contre la grippe.

Elles ont participé à toutes les réunions, ne sont pas responsables des pertes liées aux congés-maladie pour notre économie, on peut compter sur elles. Alors que des gens comme moi subissent les humeurs de leur corps, l'esprit obsédé par les besoins les plus primitifs: dormir, boire, et encore dormir.

Non, je ne veux pas rallumer ici le débat sur la vaccination. Je suis absolument convaincue qu'il existe beaucoup de bonnes raisons de se faire vacciner contre la grippe! De la part des professionnels qui travaillent avec des enfants et des personnes âgées, cela friserait en tout cas l'égoïsme que d'accepter que leur risque de maladie soit retransmis à d'autres sans la moindre mesure de confinement. Je suis fâchée, moi aussi; j'ai manqué des réunions captivantes, et pour certaines, nous devons maintenant trouver péniblement de nouvelles dates.

Je ne suis pas vaccinée. Le comble, c'est que je ne vais probablement rien y changer. Même pas l'année prochaine. Malgré tous mes arguments rationnels et ma colère. Ce sont les bizarreries de la nature humaine. Aujourd'hui, je dispose en principe d'un moyen peu coûteux, lié à un risque tout à fait acceptable éthiquement selon les connaissances actuelles, de me prémunir contre un tas d'embêtements. Et pourtant j'y renonce, délibérément et en connaissance de cause. A quoi cela peut-il bien tenir?

Suis-je femme à me laisser diriger - en dépit de toute ma reconnaissance pour le progrès, médical en particulier - par une idée romantique de la nature? Du genre: «Mon corps sait lui-même ce qui ne va pas, la grippe fébrile est le signe que je suis surmenée et que je dois me ménager»? Mes «tripes» en saventelles plus que mon cerveau? Sont-elles liées plus étroitement à mon moi véritable?

Ou est-ce une manière de me refuser à la dictature du produit national brut? Suis-je attachée à ce que mon corps garde la possibilité de s'opposer au carcan de l'efficacité? En m'imposant cette inaction, est-ce que je goûte inconsciemment une forme de rébellion contre la société hyperorganisée?

Non, en toute lucidité, ce ne sont vraiment pas là mes arguments. Dans mon âme, mes entrailles et mon corps, je me considère comme une cérébro-gastro-abdominale heureuse et convaincue. Je ne crois ni à un moi véritable dans mes tripes, ni au moi proprement dit dans mon cerveau. Mon moi empirique, le seul présent et existant, est un conglomérat de toutes les parties de mon corps, et aucune n'est ancrée plus profondément qu'une autre à une quelconque vérité extracorporelle.

Et je m'arrange avec mes échéances comme avec les mesures que m'indique mon thermomètre médical. En général, j'aime mon travail - et tout ce que je n'ai pas fait la semaine passée, je le retrouve de toute manière sur mon bureau.

\section{«Ou est-ce une manière de me refuser à la dictature du produit national brut?»}

Alors pourquoi donc, pour l'amour du ciel, ne me fais-je pas vacciner contre la grippe?

Une introspection profonde et sincère me dit que les raisons en sont bien plus prosaïques, je le crains, que les arguments «politiquement corrects» que j'ai tenté d'avancer. Je suis simplement trop paresseuse pour prétendre avoir le contrôle sur tout, trop fainéante pour planifier déjà ma journée du lendemain. Je ne suis plus malade, la grippe n'est plus qu'un lointain souvenir. Vivre au présent, c'est ne pas penser à l'avenir. C'est en tout cas ne pas laisser l'avenir influer sur le présent. Et encore moins orienter le présent sur ce que pourrait être l'avenir.

Une petite piqûre m'aurait épargné - m'épargnerait - bien des tracas. Mais j'élude la question une fois de plus. Je peux m'imaginer à quel point il peut être difficile de motiver les gens à passer des examens préventifs, et encore plus à modifier leur comportement présent pour vivre mieux, en meilleure santé et plus longtemps à l'avenir. C'est vrai pour l'individu et pour l'humanité en général. Nous sommes des êtres qui vivent le moment présent, l'avenir est bien moins réel.

Mais voilà que ma fille se retrouve au lit avec une grippe. L'avenir se fait présent. Aurais-je dû me faire vacciner quand même?

Christina Aus der $A u^{*}$ 